2. De Wit S, Hermans P, Roth D, Van Laethem $Y$, Clumeck N: Natural history of HIV infection in African patients. In: Giraldo $G$, Beth-Giraldo $E$, Clumeck N, Gharbi RM, Kyalwazi SK, de The G (ed): Second International Symposium on AIDS and Associated Cancers in Africa, Naples 1987. Karger, Basel, 1988 , p. $114-123$.

3. Piot $\mathbf{P}$, Quinn TC, Taelman H, Feinsod FM, Milangu $\mathrm{KB}$, Wobin $\mathbf{O}$, Mbendi $\mathbf{N}$, Mazebo $P$, Ndangi $K$, Stevens W, Kalambayi K, Mitchell S, Bridts C, McCormick JB: Acquired immunodeficiency syndrome in a heterosexual population in Zairc. Lancet 1984 ii: 65-69.

4. Pape JW, Liautaud B, Thomas F, Mathurin JR, St. Amand MMA, Boncy $M$, Pean $V$, Pamphile $M$, Laroche AC, Dehovitz J, Johnson WD: The acquired immunodeficiency syndrome in Haiti. Annals of Internal Medicine 1985, 103: 674-678.

5. Glatt AE, Chirgwin K, Landesman SH: Treatment of infections associated with human immunodeficicncy virus. New England Joumal of Medicine 1988, 318: $1439-1448$.

6. Young LS: Treatable aspects of infection duc to human immunodeficiency virus. Lancet 1987, ii: 1503-1506.

7. De Wit $\mathbf{S}$, Clumeck N: Fluconatole in the treatment of fungal infections associated with AIDS. Infection 1989, 17: 121-123.

8. De Wit S, Weerts D, Goossens H, Clumeck N: Comparison of fluconazole and ketoconazole for oropharyngeal candidiasis in AIDS. Lancet 1989, i: 746748.

9. Connolly GM, Hawkins D, Harcourt-Webster JN, Parsons PA, Husain OAN, Gazzard BG: Oesophegeal symptoms, their causes, treatment, and prognosis in patients with the acquired immunodeliciency syndrome. Gut 1989, 30: 1033-1039.

10. Tavitian A, Raufman JP, Rosenthal LE, Weber J, Webber CA, Dincsoy HP: Ketoconazole-resistant candida esophagitis in patients with acquired immunodeficiency syndrome. Gastroenterology 1986, 90: 443-445.

11. Lake-Bakaar G, Quadros E, Beidas S, Elsakr M, Tom W, Wilson DE, Dincsoy HP, Cohen P, Straus EW: Gastric secretory failure in patients with the acquired immunodeficiency syndrome, Annals of Internal Medicine 1988, 109: 502-504.

12. Lake-Bakaar G, Tom W, Lake-Bakaar D, Gupta N, Beidas S, Elsakr M, Straus E: Gastropathy and ketoconazole malabsorption in the acquired immunodeficiency syndrome. Amals of Intermal Medicine 1988, 109: $471-473$.

13. Hyams KC, Escamilla J, Papadimos TJ, Garcia Gonzales P, Lozada $R$, Macareno E, Bonilla N, Diaz Martinez F: New triazole antifungal agents (fluconazole and itraconazole) in the treatment of HIV-related gastrointestinal candidiasis. Scandinavian Journal of Infectious Diseases 1989, 21: 355-356.

14. Saag MS, Dismukes WE: Azole antifungal agents: emphasis on new triazoles. Antimicrobial Agents and Chemotherapy 1988, 32: 1-8.

15. Chave JP, Cajot A, Bille J, Glauser MP: Single-dose therapy for oral cindidiasis with fluconazole in HIVinfected adults: a pilot study. Journal of Infectious Diseases 1989, 159: 806-807.

\section{Leuconostoc Species as a Cause of Bacteremia: Two Case Reports and a Literature Review}

\author{
J.C.L. Bernaldo de Quirós ${ }^{1 *}$, P. Muñoz ${ }^{1}$ \\ E. Cercenado ${ }^{1}$, T. Hernandez Sampelayo ${ }^{2}$, \\ S. Moreno ${ }^{1}$, E. Bouza ${ }^{1}$
}

Two new cases of significant bacteremia caused by Leuconostoc spp. are reported and five others described in the literature are reviewed. Four of the seven patients were under one year old and presented with prolonged diarrhea related to gastrointestinal disorders. The remaining three patients were over 50 years of age and being treated in intensive care units. Six patients had nosocomially acquired catheter-related bacteremia. Leuconostoc spp. are naturally resistant to vancomycin, and five patients had received this antibiotic for prior bacteremia caused by methicillin-resistant staphylococci. The majority of patients presented with fever without severe complications. Penicillin is the treatment of choice and there is no report of any death directly attributable to infection by these microorganisms. Infection with Leuconostoc spp. should be suspected if "vancomycin-resistant streptococci" are isolated from the blood, and recorded as a potential cause of bacteremia in patients with indwelling intravenous catheters.

Leuconostoc spp. are gram-positive coccobacilli which belong to the lactic acid bacteria group (1). They are used in industrial microbiology in the production of wine, dairy products and dextrans (2). They are naturally resistant to vancomycin since the cell wall fails to provide a target for this antibiotic (1). Although they have occasionally been isolated from vaginal and stool samples (3), Leuconostoc spp. are not a regular part of the normal human flora.

Leuconostoc spp. are not generally considered to be a human pathogen (4), but sporadic cases of pneumonia $(5,6)$, meningitis ( 7$)$, infection of peritoneal dyalisis fluid $(8)$, and bacteremia $(5,6$,

\footnotetext{
${ }^{1}$ Servicio de Microbiología Cliníca, and ${ }^{2}$ Servicio de Pediatria Hospital General "Gregorio Marañon", ct Dr. Esquerdo 46. 28007 Madrid, Spain.
} 
Eur. J. Clin. Microbiol. Infect. Dis.

9-12) caused by this microorganism have recently been reported. We report two new cases of Leuconostoc bacteremia, and review five others described in the literature.

Case Reports. Case no. 1. A 2-month-old girl was admitted to hospital in February 1988 with refractory diarrhea, fever and failure to thrive. She received prolonged parenteral nutrition by different central catheters and several courses of broad-spectrum antibiotics, until a diagnosis of primary intolerance to monosaccharides was reached at seven months of age. Her clinical course was further complicated by two episodes of catheter-associated Staphylococcus epidermidis bacteremia, treated with i.v. vancomycin on both occasions. Fifteen days after the last course of vancomycin, the patient presented with a new episode of fever. Three blood cultures were obtained and vancomycin was recommenced. The growth of a vancomycin-resistant, gram-positive coccus, later identified as Leuconostoc citreum, was obtained after 24 hours, with the following MIC values: vancomycin $\geq 500 \mu \mathrm{g} / \mathrm{ml}$, penicillin $0.03 \mu \mathrm{g} / \mathrm{ml}$, ampicillin $0.03 \mu \mathrm{g} / \mathrm{ml}$, cefazolin $0.03 \mu \mathrm{g} / \mathrm{ml}$, cefotaxime $0.03 \mu \mathrm{m} / \mathrm{ml}$, imipenem $0.01 \mu \mathrm{g} / \mathrm{ml}$, erythromycin $0.03 \mu \mathrm{g} / \mathrm{ml}$, clindamycin $2 \mu \mathrm{g} / \mathrm{ml}$, gentamicin 0.25 $\mu \mathrm{g} / \mathrm{ml}$, ciprofloxacin $2 \mu \mathrm{g} / \mathrm{ml}$, rifampin $1 \mu \mathrm{g} / \mathrm{ml}$ and fosfomycin $32 \mu \mathrm{g} / \mathrm{ml}$. No tolerance to penicillin was detected. Three further blood cultures were obtained and treatment with i.v. penicillin was instituted. Leuconostoc was again isolated in this second set of blood cultures, as well as in the semiquantitative culture of the catheter tip and hub ( $>15 \mathrm{cfu} / \mathrm{plate}$ ). Cultures of the skin surrounding the insertion point of the catheter and of the parenteral nutrition fluid yjelded no growth. The patient's temperature returned to normal after withdrawal of the catheter and 15 days' treatment with i.v. penicillin. Blood cultures obtained subsequently were found to be negative. Two years later the patient is asymptomatic and in a good clinical condition.

Case no. 2. A 72-year-old male smoker was admitted to the intensive care unit in October 1988 as a result of an acute myocardial infarct. While in hospital, he developed low cardiac output and acute pulmonary edema. On the ninth day in hospital he developed a high temperature which lasted 48 hours. His temperature subsided considerably after withdrawal of the central catheter, which unfortunately was not sent for culture. A microorganism, later identified as a Leuconostoc spp. with the same MIC and MBC values for penicillin as the strain in case no. 1 was isolated in two of the three blood cultures obtained at the onset of the fever. No focus of infection was identified. As fever subsided after removal of the catheter, no antibiotic therapy was administered. The sudden death of the patient on the 12 th day in hospital was not attributable to the bacteremia. Permission for autopsy was denied.

Microbiological Investigations. Microorganisms were identified as Leuconostoc spp. by the following criteria: gram-positive coccobacilli, resistance to vancomycin, no production of catalase, negative Voges-Proskauer test, production of gas from glucose in Mann, Rogosa and Sharpe broth (Oxoid, UK), non-deamination of arginine and negative pyrrolidonylarylamidase activity $(2,4$, 13-18). The identification of the strain in case no. 1 was kindly confirmed by Dr. Facklam. The MICs of the antibiotics tested were determined by the broth microdilution method applying the NCCLS criteria (19), as were the $\mathrm{MBC}$ and tolerance. Catheters were processed for culture according to the semiquantitative method of Maki et al. (20). Hubs and swabs of skin surrounding the catheter insertion point were processed by semiquantitative techniques as described elsewhere $(21,22)$. The Bactec NR-660 (Johnston Laboratories, USA) was employed for blood cultures in our laboratory.

Discussion. In a literature search for the period 1980 to 1989 we were able to find 12 published reports of cases of bacteremia caused by Leuconostoc spp. We have only included in our review those cases in which the microbiological and clinical data necessary to confirm the identification and clinical significance of Leuconostoc were provided (9-11). Seven cases $(5,6,9)$ were excluded on these grounds. One case with an isolate originally described as vancomycin resistant Streptococcus sanguis (23) was not included although it might very well have been a case of Leuconostoc infection (24). The remaining five cases, as well as our two patients, were included in the further analysis (Table 1).

Four of the seven patients were less than one year of age. All presented with underlying diseases, of which the most common was diarrhea related to gastrointestinal pathology.

Bacteremia was nosocomially acquired in six cases. In the remaining case endocarditis was suspected in a patient with pre-existing valve pathology, but could not be confirmed. Five patients had had previous staphylococcal bac- 


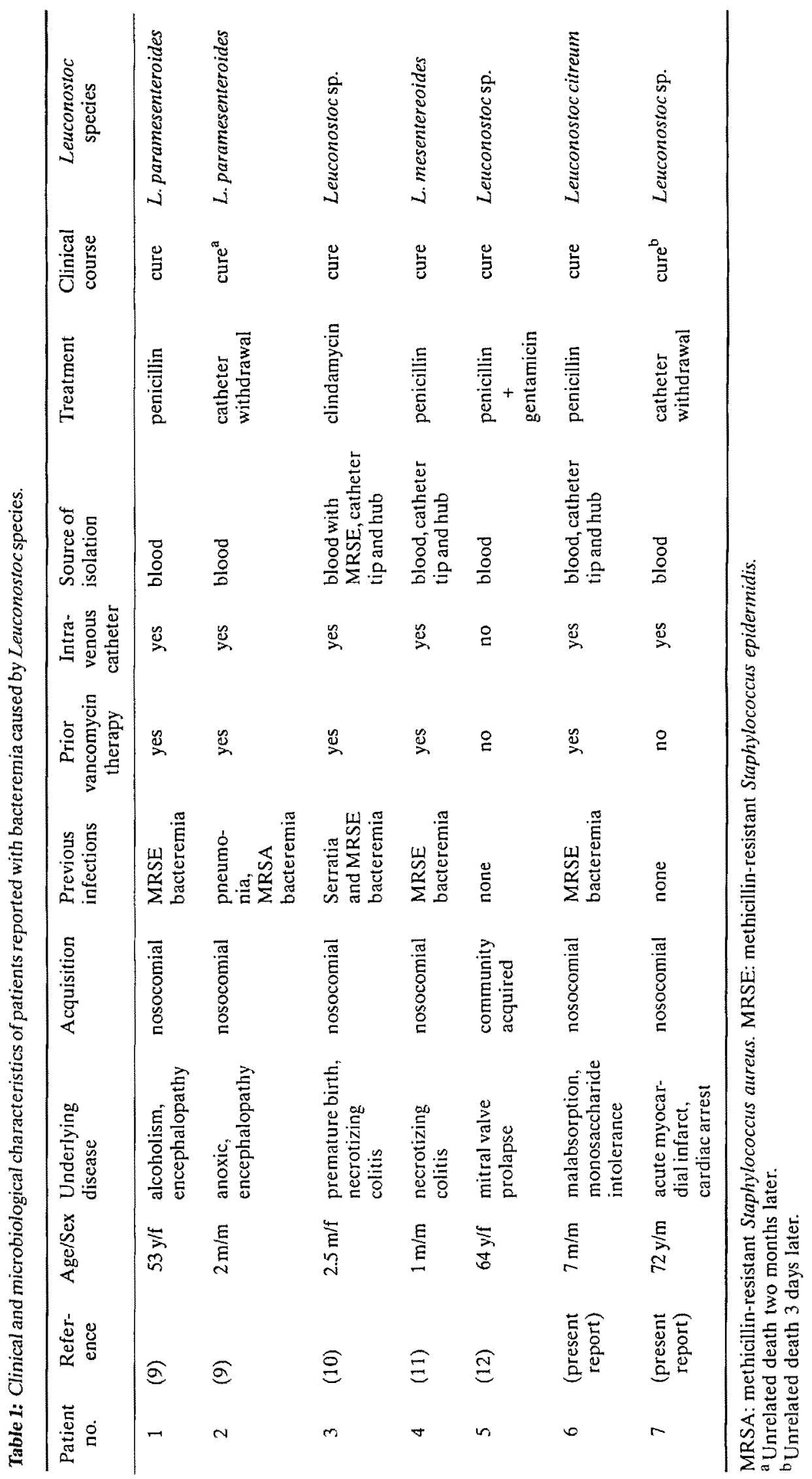


teremia (Staphylococcus epidermidis in four cases and methicillin-resistant Staphylococcus aurcus in one) and had been on or were still on treatment with vancomycin when Leuconostoc bacteremia was detected. In six patients intravenous catheters were considered to be the origin of the bacteremia.

The standard case of Leuconostoc bacteremia presented clinically as fever in a hospitalized patient, without shock, disseminated intravascular coagulation or other severe complications and with no clear portal of entry.

All seven strains were resistant to vancomycin (MIC $\geq 256 \mu \mathrm{g} / \mathrm{ml}$ ). Susceptibility test results for other antimicrobials were available for five strains, of which the majority were sensitive to penicillin, with MICs between 0.03 and $1 \mu \mathrm{g} / \mathrm{ml}$, although one tolerant strain was reported. The isolates were also sensitive to ampicillin, cefazolin, cefotaxime, imipenem, rifampicin, gentamicin and erythromycin. Three strains were sensitive to clindamycin.

Five patients received correct antibiotic treatment, in four cases with penicillin. One patient with infection caused by a penicillin-tolerant strain recovered in spite of being treated with this antibiotic. The remaining two patients received no antibiotic therapy, and catheter removal was sufficient for cure. Although two patients died in hospital, neither death could be attributed to the bacteremia.

It is only recently that Leuconostoc, a microorganism routinely used in industrial microbiology, has come to be considered a potential human pathogen (4). Occasional isolates from gastrostomy exudates $(11,25)$, peritoneal dialysis fluids (8) and others sources (7) have doubtful clinical significance. Even blood isolates cannot be routinely considered significant $(5,6,9-12)$. In only five of the 12 cases of bacteremia which we were able to find in the medical literature was the pathogenic role of this microorganism unquestionable.

The incidence of Leuconostoc bacteremia is very low ( 2 of 709 significant cases of bacteremia in 1988 in our institution), although its possible confusion with Streptococcus viridans or Enterococcus when routine sensitivity studies are not performed may contribute to underestimation of its real importance.

The majority of patients with bacteremia caused by Leuconostoc spp. are premature babies hospitalized in intensive care units with diarrhea resulting from intestinal disorders. This may be due to colonization of the newborn during labor, although Leuconostoc has only very occasionally been isolated from the vagina of healthy women (3). Another possible explanation is contamination of milk derivatives used in infant nutrition (11). The adults reported with Leuconostoc bacteremia were patients over 50 years of age in intensive care units who had indwelling intravenous catheters. Portals of entry for Leuconostoc bacteremia were either catheters ( 6 of 7 cases) or unknown ( 1 case). The most frequent clinical presentation was non-focal nosocomial fever in patients who either had been or who were still being treated with vancomycin.

Leuconostoc, in spite of being gram-positive, shows intrinsic, non-transferable resistance to vancomycin (26). This natural resistance is due to the production of cell wall peptides devoid of binding sites for vancomycin (D-alanyl-Dalanine) $(1,27)$. The production of extracellular substances which inactivate or destroy vancomycin has therefore been ruled out (26). As a result Leuconostoc behaves as a superinfection in patients being treated with vancomycin. The penicillins are adequate for treatment of Leuconostoc bacteremia. In all the cases of catheter related bacteremia analysed, the indwelling catheter was removed. We were unable to find any death unquestionably attributable to Leuconostoc bacteremia.

All gram-positive blood isolates should be tested routinely for vancomycin susceptibility and Leuconostoc spp. must be borne in mind when a vancomycin-resistant coccobacilli is detected. Leuconostoc spp. should be listed in the group of microorganisms producing bacteremia, and their presence should be specifically sought in children with central catheters and diarrhea who have previously been treated with vancomycin.

\section{References}

1. Ruoff KL: Gram-positive vancomycin-resistant clinical isolates. Clinical Microbiology Newsletler 1989, 11:14.

2. Garvie El: Separation of species of the genus Leaconostoc and differentiation of the leuconostocs from other lactic acid bacteria. Methods in Microbiology 1984, 16: 147-178.

3. Rogosa M, Sharpe ME: Species differentiation of human vaginal lactohacilli. Journal of Guneral Microbiology 1960, 23: 197-201.

4. Garvie EI: Genus Leuconostoc: In: Sneath PHA, Mair NS, Sharpe ME, Holl JG (ed): Bergey's manual of systematic bacteriology. Volume 1. Williams \& Williams, Baltimore, 1986, p. 1071-1075. 
5. Buu-Hol A, Branger $C_{3}$ Acar JF: Vancomycin-resistant streptococci or Leuconostoc sp. Antimicrobial Agents and Chemotherapy 1985, 28: 458-460.

6. Coovadia YM, Solwa Z, Van Den Ende J: Potential pathogenicity of Leuconostoc. Lancet 1988, i: 306.

7. Coovadia YM, Solwa Z, Van Den Ende J: Meningitis caused by vancomycin-resistant Leuconostoc sp. Journal of Clinical Microbiology 1987, 25: 1784-1785.

8. Dyas A, Chauhan N: Vancomycin resistant Leuconostoc. Lancet 1988, i: 306.

9. Horowitz HW, Handwerger S, Van Horn $\mathrm{KG}$, Wormser GP: Leuconostoc, an emerging vancomycinresistant pathogen. Lancet 1987, ii: $1329-1330$.

10. Hardy S, Ruoff KL, Catlin EA, Santos JI: Catheterassociated infection with a vancomycin-resistant grampositive coccus of the Leuconostoc sp. Pediatric Infectious Diseases Journal 1988, 7: 519-520.

11. Rubin LG, Velozzi E, Shapiro J, Isenberg HD: Infection with vancomycin-resistant "streptococci" due to Leuconostoc species. Journal of Infectious Diseases 1988, 157: 216.

12. Golledge CL: Bacteremia due to Leuconostoc species. Clinical Microbiology Newsletter 1989, 11: 4-5.

13. Colman G: Vancomycin-resistant leuconostocs, lactobacilli and now pediococci. Journal of Hospital Infection 1987, 10: 1-3.

14. Colman G, Ball LC: Identification of streptococci in a medical laboratory. Journal of Applied Bacteriology 1984, 57: 1-14.

15. Facklam R, Hollis D, Collins MD: Identification of gram-positive coccal and coccobacillary vancomycinresistant bacteria. Journal of Clinical Microbiology 1989, 27: $724-730$.

16. Fertally SS, Facklam R: Comparison of physiologic tests used to identify non-beta-hemolytic aerococci, enterococci, and streptococci. Journal of Clinical Microbiology 1987, 25: 1845-1850.

17. Facklam RR, Collins MD: Identification of Enterococ* cus species isolated from human infections by a conventional test scheme. Journal of Clinical Microbiology 1989, 27: 731-734.

18. Isenberg HD, Vellozzi EM, Shapiro J, Rubin LG: Clinical laboratory challenges in the recognition of Leuconostoc spp. Journal of Clinical Microbiology 1988, 26: 479-483.

19. National Committee for Clinical Laboratory Standards: Methods for dilution antimicrobial susceptibility tests for bacteria that grow aerobically. Approved standard M7-A. NCCLS, Villanova, PA, 1985.

20. Maki DG, Weise CE, Sarafin HW: A semiquantitative method for identifying intravenous-catheter-related infection. New England Journal of Medicine 1977, 140: 1305-1309.

21. Liñares J, Sitges-Serra A, Garau J, Perez JL, Martin R: Pathogenesis of catheter related sepsis: a prospective study with quantitative and semiquantitative cultures of catheter hub and segments. Journal of Clinical Microbiology 1985, 21: 357-360.

22. Cercenado E, Ena J, Rodriguez-Créixems M, Romero I, Bouza E: A conservative procedure for the diagnosis of catheter-related infection. Archives of Internal Medicine 1990, 150: 1417-1420.

23. Shlaes DM, Marino J, Jacolos MR: Infection caused by vancomycin-resistant Streptococcus sanguis II. Antimicrobial Agents and Chemotherapy 1984, 25: 527$\$ 28$.
24. Thornsberry $\mathbf{C}_{\text {, Facklam RR: Vancomycin resistant }}$ streptococci? Probably not. Antimicrobial Newsletter 1984, 8: 63-64.

25. Ruoff KL, Kuritzkes DR, Wolfson JS, Ferraro MJ: Vancomycin resistant gram-positive bacteria isolated from human sources. Journal of Clinical Microbiology 1988, 26: 2064-2068.

26. Orberg PK: Common occurrence of plasmid DNA and vancomycin resistance of Leuconostoc sp. Applied and Environmental Microbiology 1984, 48: 1129-1133.

27. Barna JCJ, Williams GH: The structure and mode of action of glycopeptide antibiotics of the vancomycin group. Annual Review of Microbiology 1984, 38: 339343.

\section{Peritonitis with CDC Group IVc-2 Bacteria in a Patient on Continuous Ambulatory Peritoneal Dialysis}

\author{
J. Zapardiel ${ }^{1}$, G. Blum ${ }^{2}$, C. Caramelo ${ }^{2}$, \\ R. Fernandez-Roblas ${ }^{1}$, J.L. Rodriguez- \\ Tudela ${ }^{1}$, F. Soriano ${ }^{1 *}$
}

A case of CDC group IVc-2 peritonitis in a patient on continuous ambulatory peritoneal dialysis (CAPD) is described. To the authors' knowledge, this is the first case reported of CAPD peritonitis in which a member of this unusual group of bacteria was isolated as the sole microorganism. As this microorganism is usually resistant to most antibiotics commonly used to treat peritonitis in patients on CAPD, microbiological investigations with identification and antimicrobial susceptibility tests are mandatory.

Human infections caused by bacteria of CDC group IVc-2 are rare. To our knowledge there are only three case reports dealing with infection caused by such microorganisms: two cases of septicemia $(1,2)$ and a third case of mixed infection with Alcaligenes faecalis and a CDC group IVc-2 organism in a patient on continuous ambulatory peritoneal dialysis (CAPD) (3). We present here the first case reported of peritonitis in which a member of CDC group IV - 2 was the sole microorganism isolated.

${ }^{4}$ Servicio de Microbiología Clínica, and ${ }^{2}$ Servicio de Nelirologia, Fundación Jiménez Diaz, Avenida Reyes Católicos 2, 28040 Madrid, Spain. 